p-ISSN: $2338-4794$

e-ISSN: 2579-7476

Vol.8. No. 3, September-Desember 2020

\title{
PENGARUH PENERAPAN SUPPLY CHAIN MANAGEMENT DAN KAIZEN TERHADAP PROSES PRODUKSI DI PT. DAIKI AXIS INDONESIA
}

\author{
Andre Auritz ${ }^{1)}$ \\ 1) Mahasiswa Program Studi Manajemen FE UNKRIS \\ Wiwik Rachmarwi ${ }^{2)}$ \\ 2) Dosen Program Studi Manajemen FE UNKRIS \\ Alamat: Kampus UNKRIS, Jatiwaringin Jakarta Timur \\ E-mail: wiwikrachmarwi@unkris.ac.id
}

\begin{abstract}
This research aims to know the effect of supply chain management and kaizen on company's production. The Research method used is multiple linear regression analysis and simple linear regression analysis. The research result showed that supply chain management and kaizen togethers react positive and significant effect on production. The result is that partially supply chain management and kaizen each react positively and play significant role to production.
\end{abstract}

Keyword: Supply chain management, kaizen, production.

\section{PENDAHULUAN}

Kegiatan produksi tidak lepas dari langkah atau tahapan proses produksi, karena barang yang tercipta dari langkah atau tahapan proses produksi. Sebuah perusahaan yang memperhatikan secara penuh terhadap produk atau jasa yang dihasilkan dengan baik akan memberikan dampak positif kepada perusahaan di dunia bisnis. Produk merupakan suatu barang atau jasa yang dikeluarkan dari hasil sebuah proses produksi atau hasil produksi ditawarkan kepada konsumen berupa benda yang terlihat ataupun benda yang tidak terlihat untuk memenuhi sebuah keinginan dan kebutuhan konsumen. Produksi menurut Heizer dan Render (2015) merupakan sebuah "penciptaan barang atau jasa". Menurut Yamit (2005), produksi yaitu "tindakan yang menyertakan peralatan, bahan, dan tenaga manusia untuk menghasilkan produk yang berguna". Produk yang diciptakan dapat berupa material dan dapat juga berupa jasa (intangible material). Intinya produk yang mempunyai nilai lebih atau mengalami penambahan nilai dari proses transformasi bahan atau komponen menjadi produk lain disebut produksi. Produksi dimaknai sebagai suatu aktifitas atau kegiatan dimana terjadinya suatu perubahan proses atau transformasi dengan adanya beberapa faktor pendukung dalam kelancaran produksi diantaranya faktor capital, sumber daya alam, kekuatan manusia, supply chain management, kaizen, dan lain-lain, atau produksi adalah proses input (bahan baku) menjadi output (barang atau jasa) yang mempunyai nilai ekonomi lebih.

Perusahaan dalam menerapkan proses produksi berharap mencapai sasaran yang maksimal dengan memakai sumber-sumber secara efektif dan praktis. Dalam mencapai suatu hal ada beberapa faktor yang dapat menunjang kelancaran suatu produksi oleh perusahaan salah satu faktor diantaranya yaitu menerapkan 
supply chain management. Heizer dan Render (2015) "memaparkan aktifitas supply chain management suatu pengaturan dari keseluruhan diawali dari proses bahan baku dan diakhiri sampai ke konsumen untuk mendapatkan hasil yang maksimal, sehingga sebuah rantai pasokan meliputi manufacturing companies, pemasok, agen, pengecer, dan pelanggan akhir". Selain penerapan supply chain management, ada faktor lain yang dapat menunjang dan mempengaruhi kelancaran proses produksi yaitu penerapan kaizen. Menurut Heizer dan Render (2015) kaizen merupakan "perubahan menuju kearah yang lebih baik lagi, atau yang lebih umum dikenal sebagai perbaikan berkesinambungan secara terusmenerus". Tujuan dalam penelitian ini adalah untuk menganalisis pengaruh penerapan supply chain management dan kaizen terhadap proses produksi di PT. Daiki Axis Indonesia.

\section{LANDASAN TEORI}

\section{Proses Produksi}

Menurut Gunawan (2016) produksi merupakan "suatu cara, pola, dan sistem guna menghasilkan barang atau jasa yang bermanfaat memakai beberapa sumber seperti tenaga manusia, uang, peralatan, dan bahan baku yang ada". Menurut Biegel (2009) produksi merupakan "suatu keadaan dimana input atau masukan menggunakan bahan baku dirubah menjadi output (keluaran) berupa barang jadi dengan menggunakan peralatan, waktu, keahlian, uang, dan manajemen". Menurut Tampubolon (2014) produksi merupakan "kegiatan yang menggunakan berbagai jenis komponen bahan dan peralatan produksi yang ditata, dirancang sedemikian rupa, dengan memperhatikan susunan kegiatan (routing) untuk dapat dimanfaatkan secara fleksibel (multipurpose) sehingga dapat menciptakan produk, serta aliran bahan di dalam proses yang sesuai tolak ukur". Menurut Handoko (2012) produksi yaitu "proses aliran produk atau urutan-urutan yang telah ditentukan sebelumnya, melaju dari satu operasi ke operasi berikutnya dengan produk harus distandardisasi dengan baik, dengan alur kegiatan dari bahan mentah menjadi produk akhir dan susunan operasi yang digunakan untuk menghasilkan produk". Menurut Assauri (2008), indikator produksi terdiri dari kualitas produk, total output yang dihasilkan, dan akurasi penyerahan barang.

\section{Supply Chain Management}

Heizer dan Render (2015), "memaparkan aktifitas supply chain management suatu pengaturan dari keseluruhan diawali dari proses bahan baku dan diakhiri sampai ke konsumen untuk mendapatkan hasil yang maksimal, sehingga sebuah rantai pasokan meliputi manufacturing companies, pemasok, agen, pengecer, dan pelanggan akhir". Menurut Martono (2015), supply chain management merupakan "mekanisme terpadu yang mengkoordinasikan keseluruhan proses mulai dari perancangan, distribusi bahan baku dari supplier, perubahan bahan baku menjadi produk, pergudangan, sistem informasi dan pembayaran barang, diorganisasi atau instansi dalam merencanakan dan mendistribusikan barang ke pelanggan, serta layanan pengembalian produk". Haming dan Nurnajamuddin (2012), supply chain management adalah "kegiatan pengendalian operasi, perencanaan, dan penerapan yang bertujuan untuk mencukupi kebutuhan pelanggan seefisien mungkin". Menurut Irawan (2008), supply chain management yaitu "aktifitas proses pelaksanaan untuk mendapatkan dan mentrasformasikan bahan mentah menjadi produk, dan mendistribusikan produk tersebut ke pelanggan". Menurut Tampubolon (2014), "untuk mengintegrasikan 
pemasok, produsen, serta gudang dengan toko-toko untuk meminimalkan waktu dan jangkauan sistem dengan biaya sesuai persyaratan, sehingga produk yang dihasilkan dapat di distribusikan ke tempat dengan waktu yang efektif merupakan pengertian supply chain management". Menurut Haming dan Nurnajamuddin (2012), indikator supply chain management terdiri dari kebutuhan, produksi, dan kerja sama.

Penelitian yang dilakukan Zulfahmi, et al (2018) menghasilkan bahwa supply chain management sangat memungkinkan tercapainya peningkatan dalam proses produksi, serta terkait perancangan produksi yang akan membantu kegiatan produksi diperoleh dari hasil informasi yang diterima. Penelitian yang dilakukan Sudrajat, et al (2018) menghasilkan bahwa sistem manajemen rantai pasokan bertujuan untuk mengetahui informasi seluruh kegiatan produksi, mampu mengontrol jumlah produk yang sedang diproduksi, produk yang sudah diproduksi, serta mengontrol jumlah stok bahan penunjang dan stok produk yang tersedia di gudang secara real time, sehingga dalam proses produksi diperlukan suatu data yang terpusat.

\section{Kaizen}

Menurut Heizer dan Render (2015), kaizen merupakan "perubahan menuju kearah yang lebih baik lagi, atau yang lebih umum dikenal sebagai perbaikan berkesinambungan secara terusmenerus". Menurut Fatkhurrohman dan Subawa (2016), kaizen ialah "perbaikan yang dilakukan untuk memperbaiki kualitas produk dengan cara menghilangkan beban kerja yang berlebih, menghapuskan pemborosan yang tidak memberikan nilai tambah produk karena munculnya anggaran pengeluaran yang berakibat berkurangnya pemasukan. Barang yang diciptakan memiliki nilai jual yang tinggi dengan mutu produk yang baik, dengan cara menurunkan biaya produksi yang bertujuan untuk meningkatkan kualitas, yang dimana sasaran utama dari hal-hal tersebut ialah meningkatkan kepuasan pelanggan dan meningkatkan kesetiaan konsumen". Kaizen dapat diterapkan di awal, saat, hingga akhir proses produksi barang tersebut disimpan digudang dan siap dikirim ke pelanggan. Menurut Imai dalam Sari dan Sirait (2016), "istilah perbaikan berkelanjutan merupakan makna dari kaizen. Dalam bahasa Jepang, Kai merupakan perubahan dan Zen berarti baik. Mekanisme perbaikan secara berkelanjutan dan penyelesaian perbaikan yang berkesinambungan dengan melibatkan setiap orang pada mutu, proses, budaya instansi, produktifitas, keamanan, teknologi, dan kepemimpinan menggambarkan pengertian dari kaizen". Metode ilmiah digunakan sebagai metode pembelajaran untuk mengetahui bagaimana menemukan dan menghilangkan pemborosan dalam proses apabila dilakukan dengan baik, maka tekanan kerja dapat dihapuskan dan memberi pengetahuan pada orang lain tentang bagaimana melakukan percobaan pada pekerjaan mereka. Menurut Gaspers (2003) dalam Faritsy dan Suseno (2015), "pada perusahaan, baik perusahaan manufaktur atau bukan, dilakukan perbaikan secara terus-menerus (continuous improvement), yang dimulai dengan standardisasi, 5R, dan menghilangkan pemborosan merupakan istilah kaizen". Menurut Imai (2018), kaizen adalah "setiap orang baik manajer maupun karyawan memerlukan penyempurnaan, berkesinambungan secara khusus". Dalam kehidupan baik cara bekerja, kehidupan sosial, maupun kehidupan rumah tangga perlu dibenahi setiap saat merupakan penjelasan filosofi dari kaizen. Konsep yang meliputi sebagian besar praktis ciri khas Jepang yang belakangan ini terkenal diseluruh dunia dengan istilah konsep payung. 
Menurut Masaaki Imai (2018), indikator kaizen terdiri dari seiri yang artinya ringkas, seiton yang artinya rapi, seiso yang artinya resik, seiketsu yang artinya rawat, dan shitsuke yang artinya rajin.

Penelitian yang dilakukan Puvanasvaran, et al (2010) menghasilkan bahwa sistem kaizen berpengaruhi terhadap proses produksi dalam hal waktu produksi berkurang sekitar 14,93\% menghilangkan kerugian dan limbah baik dalam produksi atau non produksi. Hal terpenting dalam kaizen adalah melakukan perbaikan terus menerus. Untuk melakukan perbaikan berkelanjutan di perusahaan, pertamatama adalah mengatur pola pikir yang benar. Beberapa pola pikir kaizen sedemikian rupa sehingga semuanya bisa dan harus ditingkatkan, dan juga harus menekankan pada proses yang membentuk cara berpikir yang mengharah pada sistem manajemen yang kontributif, peningkatan proses, dan menanggapi upaya yang berorientasi pada proses orang untuk perbaikan. Penelitian yang dilakukan oleh Yohendry, et al (2017) menghasilkan penelitiannya yaitu secara simultan (bersama-sama), perusahaan telah dianggap berhasil melakukan implementasi kaizen dengan cara mengurangi pemborosan, mengurangi ketidakraturan, dan mengurangi beban yang berlebihan yang berimplikasi terhadap efisiensi biaya produksi meningkat (hasil produksi naik, biaya produksi menurun).

\section{METODE PENELITIAN}

\section{Rancangan Penelitian}

Penelitian ini dirancang untuk menjelaskan pengaruh penerapan supply chain management dan kaizen terhadap produksi di PT. Daiki Axis Indonesia baik secara parsial maupun secara simultan. Data yang digunakan dalam penelitian ini merupakan data primer melalui pengisian kuesioner kepada para karyawan PT. Daiki Axis Indonesia divisi produksi.

\section{Metode Pengumpulan Data}

Penelitian ini dilakukan di PT. Daiki Axis Indonesia yang berlokasi di daerah Kawasan Industri Modern Cikande (KIMC), Serang-Banten. Data yang dikumpulkan adalah data primer yang didapat melalui pengisian kuesioner oleh karyawan PT. Daiki Axis Indonesia dengan menggunakan model skala Likert. Adapun skala yang digunakan adalah sangat setuju dengan poin 5 , yang menjawab setuju dengan poin 4 , yang menjawab netral dengan poin 3 , yang menjawab tidak setuju dengan poin 2 , yang menjawab sangat tidak setuju dengan poin 1. Menurut Sugiyono (2015), "skala model Likert dapat dipakai buat menilai suatu perilaku, tanggapan, dan gagasan, serangkaian orang tentang gejala sosial". Indikator yang dijadikan sebagai titik pangkal untuk menyusun perangkat item yang dapat berupa pernyataan dengan skala Likert. Variabel yang akan diukur, diuraiakan menjadi indikator variabel. Menurut Sugiyono (2015), "materi atau pokok yang mempunyai karateristik khusus dalam suatu wilayah dan kemudian ditetapkan oleh peneliti untuk dipelajari dan dipahami selanjutnya menarik kesimpulan adalah pengertian dari populasi".

Populasi untuk penelitian ini adalah karyawan Divisi Produksi PT. Daiki Axis Indonesia yang berjumlah 150 orang. Menurut Sugiyono (2015), "sampel merupakan penelitian menggunakan sampel yang diambil dari populasi dimana dapat ditarik kesimpulan bisa dipergunakan untuk populasi. Dengan keterbatasan jangka waktu, energi, dan biaya dengan populasi besar maka bagian dari total dan karakteristik yang dimiliki oleh populasi tetapi peneliti tidak mungkin mengamati semua yang ada 
pada populasi, sehingga sampel yang diambil dari populasi wajib representatif'. Berdasarkan hasil rekapitulasi dengan menggunakan rumus Isaac dan Michael dengan total dari populasi 150 orang, tingkat kesalahan 10 $\%$, maka diketahui ukuran atau total sampel dalam penelitian ini yaitu sebesar 97 responden.

$$
S=\frac{\lambda \cdot N \cdot P \cdot(1-P)}{d^{2}(N-1)+\lambda^{2} \cdot P(1-P)}
$$

Sumber: Sugiyono (2015)

Dengan diketahui total dari data karyawan PT. Daiki Axis Indonesia, maka dalam penelitian ini memakai metode teknik probability sampling. Menurut Sugiyono (2015) "teknik pengambilan sampling merupakan teknik dalam sampel". Peluang yang menyerupai bagi setiap unsur atau elemen untuk dipilih menjadi anggota sampel dengan memakai teknik pengambilan sampel merupakan arti dari teknik probability sampling". Populasi yang dilakukan secara random dalam pengambilan anggota sampel bisa dilakukan tanpa memperhatikan strata yang terdapat dalam populasi disebut teknik dengan menggunakan simple random sampling.

Guna memberikan hasil yang relevan dan obyektif dalam metode pengumpulan data penelitian analisis penerapan supply chain management dan kaizen terhadap produksi PT. Daiki Axis Indonesia, maka dalam penelitian ini menggunakan studi literatur dan studi lapangan Dalam penelitian pengumpulan data studi lapangan menggunakan teknik pengumpulan data berupa wawancara tidak terstruktur dilakukan dengan cara kuesioner (angket), bertatap muka (face to face), dan pengumpulan data observasi partisipan (Participant Observation).

Untuk memberikan hasil yang relevan dan obyektif dalam teknik analisis data tentang penelitian analisis penerapan supply chain management dan kaizen terhadap produksi di PT. Daiki Axis Indonesia, maka teknik analisisi data kuantitatif dipakai dalam penelitian ini. Data diperoleh dari berbagai sumber, dengan memakai teknik pengumpulan data. Instrumen yang dipakai dalam memperoleh data (mengukur) valid. Instrumen yang valid berarti dapat dipakai untuk mengukur apa yang sebenarnya diukur. Menurut Sugiyono (2015) "validitas adalah tingkatan akurasi antara data yang terjadi pada objek penelitian dan data yang dapat di informasikan oleh peneliti". Menurut Sugiyono (2015) "perangkat atau instrumen apabila dipakai berulang-ulang untuk menghitung obyek yang sama, akan mendapatkan informasi yang serupa merupakan pengertian uji reliabilitas".

\section{Model Analisis Data}

Untuk menganalisis pengaruh penerapan supply chain management dan kaizen terhadap proses produksi di PT Daiki Axis Indonesia digunakan metode analisis regresi linier berganda, dimana analisis linier berganda guna melihat tidak ada atau adanya efek keseluruhan variabel X (variabel bebas) dimana dalam hal ini variabel supply chain management dan kaizen atas varibel $\mathrm{Y}$ (variabel terikat) dimana dalam hal ini variabel produksi. Pembuktian dari pengaruh penerapan supply chain management dan kaizen terhadap produksi di PT. Daiki Axis Indonesia, kemudian dipakai analisis regresi linier berganda.

$\mathrm{Y}=\mathrm{b}_{\mathrm{o}}++\mathrm{b}_{1} \mathrm{X}_{1}+\mathrm{b}_{2} \mathrm{X}_{2}$

di mana:

$\mathrm{Y} \quad=$ Proses produksi

$\mathrm{X}_{1} \quad=$ Supply chain management

$\mathrm{X}_{2} \quad=$ Kaizen

$\mathrm{b}_{\mathrm{o}} \quad=$ Konstanta

$b_{1}, b_{2},=$ Koefisien regresi 


\section{HASIL PENELITIAN DAN PEMBAHASAN}

\section{Hasil Penelitian}

Uji validitas dan uji reliabilitas
Variabel penelitian yang terdiri dari produksi, supply chain management, dan kaizen keseluruhan memiliki 39 butir pernyataan. Hasil pengujian terhadap 39 butir pernyataan dinyatakan valid dimana r-hitung > t-tabel $(0,1680)$ dan uji reliabel memiliki nilai Cronbach's Alpha > 0,6.

Tabel 2: Hasil Uji Reliabilitas

\begin{tabular}{lccc}
\hline \multicolumn{1}{c}{ Variabel } & $\begin{array}{c}\text { Cronbach } \\
\text { Alpha }\end{array}$ & Nilai Kritis & Keterangan \\
\hline Supply Chain Management & 0,710 & 0,6 & Reliabel \\
\hline Kaizen & 0,706 & 0,6 & Reliabel \\
\hline Produksi & 0,671 & 0,6 & Reliabel \\
\hline
\end{tabular}

Sumber: Data primer diolah, 2020

\section{Uji asumsi}

Untuk uji normalitas diperoleh angka Asymp. Sig. (2-tailed) sebesar 0,108 dimana > dari 0,05 yang berati distribusi dari metode KolmogorovSmirnov adalah berdistribusi normal. Uji multikolinieritas diperoleh angka tolerance value sebesar $0.927>0,10$ dan nilai VIF sebesar $1.079<10$. Yang berarti Tolerance value $>0,10$ atau nilai VIF < 10 sehingga dapat disimpulkan data tersebut dinyatakan bebas atau tidak terjadi multikolinieritas. Untuk uji Autokorelasi diketahui nilai DurbinWatson sebesar 1,947 dengan nilai signifikansi 5\% $(0,05)$ dengan jumlah sampel 97 responden, dan jumlah variabel independent $2(\mathrm{~K}=2) \mathrm{X} 1$ (Supply Chain Management) dan X2 (Kaizen), maka diketahui nilai dl sebesar 1.627, dan nilai du sebesar 1.711. serta diketahui nilai $4-d l=2.373$, dan nilai $4-d u=2.289$. jadi Kesimpulannya adalah du $<$ DW $<4$ du $(1.711<1,947<2.289)$ sehingga data tersebut tidak terdapat gejala autokorelasi. Untuk uji Heterokedasitas hasil uji heteroskedastisitas berupa gambar grafik scatterplots, terlihat bahwa titik-titik menyebar secara acak baik tersebar diatas maupun dibawah angka 0 pada sumbu Y. Dengan hasil ini dapat disimpulkan bahwa Jika tidak ada pola yang jelas, serta titik-titik menyebar di atas dan dibawah angka 0 pada sumbu Y, maka data tersebut bisa dikatakan tidak terjadi heteroskedastisitas.

\section{Analisis regresi linear berganda}

Untuk mengetahui ada atau tidaknya hubungan signifikan secara simultan antara variabel supply chain management dan variabel kaizen terhadap variabel proses produksi, maka dilakukan pengujian F-hitung terhadap Ftabel dengan nilai tingkat kepercayaan nilai $\alpha$ sebesar 0,05 , diperoleh hasil Ftabel $=3,09$ yang dapat diketahui dari tabel distribusi $t$ (derajat kebebasan $=n-2)$ dengan uji dua pihak. Berdasarkan perhitungan tersebut, diperoleh hasil yaitu nilai signifikan sebesar $0,000<$ 0,05, F-hitung sebesar 53.040 dan F-tabel sebesar 3,09. Jadi jika nilai signifikan < 0,05 dan F-hitung > F-tabel, maka dapat diartikan bahwa secara bersama-sama variabel supply chain management dan kaizen berpengaruh terhadap variabel proses produksi. Nilai koefisien determinasi $\left(\mathrm{R}^{2}\right)$ sebesar 0.530 , artinya supply chain management dan kaizen memberikan kontribusi sebesar $53 \%$ kepada produksi PT. Daiki Axis 
Indonesia, sedangkan sisanya sebesar tidak dibahas dalam penelitian ini.

$47,0 \%$ disumbangkan faktor lain yang

Tabel 3: Pengaruh Supply Chain Management dan Kaizen Terhadap Produksi PT. Daiki Axis Indonesia

\begin{tabular}{|c|c|c|c|c|c|}
\hline \multirow[b]{2}{*}{ Variabel } & \multicolumn{5}{|c|}{ Parameter } \\
\hline & R Square & Konstanta & $\begin{array}{c}\text { Koef. } \\
\text { Regresi }\end{array}$ & Sig. & $\alpha$ \\
\hline Supply Chain Manajemen & \multirow{2}{*}{0.530} & \multirow{2}{*}{2.541} & 0.525 & \multirow{2}{*}{0.000} & \multirow{2}{*}{0.05} \\
\hline Kaizen & & & 0.348 & & \\
\hline \multicolumn{3}{|c|}{ F-hitung $=53.040>$ F-tabel $=3,09}$. & & \multicolumn{2}{|l|}{0,000} \\
\hline Sumber: data diolah 2020 & & & & & \\
\hline
\end{tabular}

Persamaan regresi:

$Y=2,541+0,525 X_{1}+0,348 X_{2}$

Supply chain management dan kaizen berpengaruh positif dan signifikan terhadap produksi PT. Daiki Axis Indonesia, pada tingkat nyata $99 \%$. Koefisien supply chain management sebesar 0,525 artinya jika ada peningkatan supply chain management, maka produksi PT. Daiki Axis Indonesia akan meningkat atau sebaliknya dengan asumsi kaizen tidak berubah. Koefisien kaizen sebesar 0,348, artinya jika ada peningkatan kaizen, maka produksi PT. Daiki Axis Indonesia akan meningkat atau sebaliknya dengan asumsi kaizen tidak berubah.

\section{Analisis regresi linear sederhana}

Tabel 4: Pengaruh Supply Chain Management Terhadap Produksi PT. Daiki Axis Indonesia

\begin{tabular}{lccccc}
\hline \multirow{2}{*}{ Variabel } & R Square & Konstanta & $\begin{array}{c}\text { Koef. } \\
\text { Regresi }\end{array}$ & Sig. & $\boldsymbol{\alpha}$ \\
\cline { 2 - 6 } & 0.345 & 19.218 & 0.552 & 0.000 & 0.05 \\
\hline Supply chain management & & & & & \\
\hline Pengujian Signifikansi & & & & \\
\hline t-hitung $=7,069>$ t-tabel $=1,985$ & & & & \\
\hline Sumber: Data primer diolah, 2020
\end{tabular}

Persamaan regresi: $\mathrm{Y}=19,218+0,552 \mathrm{X}_{1}$

Berdasarkan Tabel 4, nilai koefisien determinasi $\left(\mathrm{R}^{2}\right)$ sebesar 0.345 , artinya supply chain management memberikan konstribusi sebesar 34,5\% kepada produksi PT. Daiki Axis Indonesia, sedangkan sisanya sebesar $65,5 \%$ disumbangkan faktor lain. Supply
Chain Management berpengaruh positif dan signifikan pada tingkat nyata $99 \%$ terhadap produksi PT. Daiki Axis Indonesia. Koefisien supply Chain Management sebesar 0,552, artinya jika ada peningkatan supply chain management, maka produksi PT. Daiki Axis Indonesia akan meningkat atau sebaliknya. 
Tabel 5: Pengaruh Kaizen Terhadap Produksi PT. Daiki Axis Indonesia

\begin{tabular}{lccccc}
\hline \multirow{2}{*}{ Variabel } & R Square & Konstanta & $\begin{array}{c}\text { Koef. } \\
\text { Regresi }\end{array}$ & Sig. & $\boldsymbol{\alpha}$ \\
\cline { 2 - 6 } & 0.220 & 23.973 & 0.379 & 0.000 & 0.05 \\
\hline Kaizen & & & & \\
\hline Pengujian Signifikansi & & & & \\
\hline t-hitung $>$ t-tabel $=5.181>1.985$ & & & \\
\hline Sumber: Data primer diolah, 2020 &
\end{tabular}

Persamaan regresi: $\mathrm{Y}=23,973+0,379$ $\left(\mathrm{X}_{2}\right)$

Berdasarkan Tabel 5, nilai koefisien determinasi $\left(\mathrm{R}^{2}\right)$ sebesar 0.220, artinya kaizen memberikan konstribusi sebesar 22,0\% terhadap produksi PT. Daiki Axis Indonesia, sedangkan sisanya sebesar 78,0\% disumbangkan faktor lain. Kaizen berpengaruh positif dan signifikan pada tingkat nyata $95 \%$ terhadap produksi PT. Daiki Axis Indonesia. Koefisien kaizen sebesar 0,379, artinya jika ada peningkatan kaizen, maka produksi PT. Daiki Axis Indonesia akan meningkat atau sebaliknya.

\section{Pembahasan}

Pengaruh supply chain management dan kaizen terhadap produksi PT. Daiki Axis Indonesia

Peningkatan supply chain management dan kaizen mendorong peningkatan produksi. Dalam produksi tercapainya hasil produk yang optimal, meminimalisir beban biaya produksi, dan mempunyai harga jual produk yang tinggi dengan mutu yang terbaik, dengan cara dilakukannya perbaikan kualitas produk atau jasa secara terus-menerus (continuous improvement), menghilangkan beban kerja yang berlebih atau pemborosan dan melibatkan setiap orang baik manajer maupun karyawan.

\section{Pengaruh supply chain management terhadap produksi PT. Daiki Axis Indonesia}

Peningkatan supply chain management mendorong peningkatan produksi. Dalam produksi tercapainya sistem terintegrasi yang mengkoordinasikan keseluruhan proses planning, sumber input bagi proses, distribusi bahan baku dari supplier, perubahan bahan baku menjadi produk, distribusi, pergudangan, sistem informasi dan pembayaran produk, di kelompok atau instansi dalam merencanakan dan memberikan produk tersebut dikonsumsi oleh konsumen dengan tujuan untuk kelancaran produksi dan tercapainya hasil produk yang maksimal. Penelitian ini mendukung hasil penelitian sebelumnya oleh Kasmari dan Indriyaningrum (2020) dengan judul penelitian pengaruh supply chain management dan prioritas bersaing terhadap produksi.

\section{Pengaruh kaizen terhadap Produksi PT. Daiki Axis Indonesia}

Peningkatan kaizen mendorong peningkatan produksi. Dengan perbaikan mutu produk secara terus-menerus (continuous improvement) menuju perubahan kearah yang lebih baik lagi, menghilangkan beban kerja yang berlebih atau pemborosan dengan melibatkan setiap orang baik manajer maupun karyawan, sehingga produk yang dihasilkan memiliki harga jual yang lebih dengan mutu terbaik. Penelitian dengan hasil yang sama pernah dilakukan oleh Karimah, dan Pujiyanto (2017) dalam penelitian dengan judul pengaruh kaizen 
pada brake assembly line untuk meningkatkan produksi.

\section{KESIMPULAN DAN SARAN}

\section{Kesimpulan}

Supply chain management dan kaizen mendukung peningkatan produksi PT. Daiki Axis Indonesia, baik secara parsial maupun secara simulkan. Supply chain management merupakan faktor paling dominan mendukung peningkatan produksi PT. Daiki Axis Indonesia,

\section{Saran}

Khususnya untuk manajemen atau pimpinan di PT. Daiki Axis Indonesia dengan adanya penelitian ini diharapkan dapat menambah bahan masukan positif. Dalam produksi dilakukan perbaikan kualitas produk atau jasa secara terusmenerus (continuous improvement) untuk tercapainya produk yang optimal, meminimalisir beban biaya produksi, mempunyai nilai jual dan mutu yang baik. Dalam kegiatan produksi masih perlu diberikan pelatihan dan pemahaman secara terus menerus terhadap standar operasional perusahaan agar pelaksanaan kegiatan produksi dapat berjalan dengan baik. Kegiatan resik dan kebersihan terjadwal setiap hari. Memiliki schedule perencanaan cadangan dan hasil penelitian ini dapat dijadikan referensi untuk peneliti berikutnya dengan menambah variabel penelitian yaitu TQM dan SOP.

\section{DAFTAR PUSTAKA}

Agus, Arawati, 2015, Supply Chain Management: The Influence of SCM on Production Performance and Product Quality, Journal of Economics, Business and Management, DOI: 10.7763/JOEBM 2015.V3.332, Vol. 3, No. 11, November 2015. Malaysia.
Assauri, Sofjan. 2008, Manajemen Produksi dan Operasi, Penerbit: Fakultas Ekonomi Universitas Indonesia, Jakarta.

Bhuono Agung, Nugroho, 2005, Strategi Jitu Memilih Metode Statistik Penelitian Dengan SPSS, Penerbit: Andi, Yogyakarta.

Biegel, John E, 2009, Pengendalian Produksi (Suatu Pendekatan Kuantitatif), Cetakan kedua, Penerbit: Akademika Pressiondo, Jakarta.

Fatkhurrohman, Arief, Subawa Prakosos, 2016 Penerapan Kaizen Dalam Meningkatkan Efisiensi Dan Kualitas Produk Pada Bagian Banbury PT. Bridgestone Tire Indonesia, Jurnal Administrasi Kantor, Vol. 4, No.1, Juni 2016, 14-3, P-ISSN: 2337-6694, E-ISSN: 2527-9769.

Gautam, Rajesh, Sushil Kumar, Sultan Singh, 2012, Kaizen Implementation in an Industry in India: A Case Study India, International Journal of research In Mechan Ical engineering \& technology ISSN: 2249-5762 (Online), ISSN: 2249-5770 (Print), India.

Gujarati. 2012, Dasar-Dasar Ekonometrika, Terjemahan: Mangunsong. Edisi: Lima. Penerbit: Salemba Empat. Jakarta.

Gunawan, Cakti Indra, 2016, Teori Dasar Manajemen Produksi dan Operasinal, Cetakan Pertama, Penerbit: CV. IRDH (Research and Publishing) Anggota IKAPI. Purwekoerto.

Haming, Nurdifin, Mahfud Nurnajamuddin, 2012, Manajemen Produksi Modern (Operasi Manufaktur dan Jasa), Edisi kedua, Cetakan Pertama, Penerbit: PT. Bumi Aksara. Jakarta. 
Handoko, T Hani, 2012, Dasar-Dasar Manajemen Produksi dan Operasi, Edisi Pertama, Cetakan ketujuh belas, Penerbit: BPFE, Yogyakarta.

Heizer, Jay \& Reinder, Barry, 2015, Manajemen Operasi (Manajemen Keberlangsungan dan Rantai Pasokan), Edisi 11, Edisi Bahasa Indonesia, Penerbit: Salemba Empat, Jakarta.

Imai, Masaaki, 2018, Kaizen Kunci Sukses Jepang Dalam Persaingan, Cetakan Ke-5, Dialih bahasakan oleh Mariani Gandamihardja, Penerbit: PPM, Jakarta.

Irawan, A.P, 2008, Buku Ajar Manajemen Rantai Pasokan, Penerbit: Fakultas Teknik Universitas Tarumanegara, Jakarta.

Karimah, Fadhilah Al, Eko Pujiyanto, 2017, Aplikasi Kaizen pada Brake Assembly Line untuk Meningkatkan Produktivitas Line (Studi Kasus: PT. XYZ), Seminar Nasional Teknik Industri Universitas Gadjah Mada, 08 November 2017, ISBN: 978-602-73461-6-1, Yogyakarta.

Martono, R. 2015, Manajemen Logistik Terintegrasi, Jakarta. Penerbit: PPM Manajemen.

Nurmaidah, Mawar, Tacbir Hendro Pudjiantoro, dan Faiza Renaldi, 2017, Pembangunan Sistem Manajemen Rantai Pasok Dalam Proses Produksi Teh Di PT. Perkebunan Nusantara VIII, Seminar Nasional Teknologi Informasi dan Multimedia, 4 Februari 2017, ISSN: 2302-3805, Cimahi.

Pramesti, Getut, 2018, Mahir Mengelola Data Penelitian Dengan SPSS 25, Penerbit: PT. Elex Media Komputindo, Jakarta.

Pratama, Hendra, Tri Widodo, 2018, Analisis Lean - Pemetaan Alir Nilai Untuk Pengurangan Biaya Pada Manajemen Rantai Pasok Bahan Baku Pengrajin Tas UMKM,
Prosiding Seminar Nasional Unimus, Volume 1, 2018, E-ISSN: 2654-3257, P-ISSN: 2654-3168, Tangerang.

Puvanasvaran, A.P, Robert S.T. Kerk, dan A.R. Ismail, 2010, A Case Study of Kaizen Implementation in SMI, National Conference in Mechanical Engineering Research and Postgraduate Studies, (2nd NCMER 2010) 3-4 December 2010, PP.374-392, ISBN: 978-9670120-04-1, Faculty of Mechanical Engineering, UMP Pekan, Kuantan, Pahang, Malaysia.

Sakti, 2016, Konsep Supply Chain Management (SCM) pada Proses Produksi dalam Pengelolaan Persediaan Bahan Baku, Jurnal Teknologi Informasi, Volume 12, Nomor 2, Agustus 2016, ISSN: 1979-1496.

Santoso, Singgih. 2010. Statistik Multivariat. Penerbit: PT Elex Media Komputindo. Jakarta.

Santoso, Singgih. 2012. Statistik Parametrik. Penerbit: PT Gramedia Pustaka Umum. Jakarta.

Sari, Diana Puspita, Ropenti Sirait, 2016, Aplikasi Pendekatan Six Sigma dan Kaizen Untuk Peningkatan Kualitas Pada Proses Produksi Produk Botol Minum Plastik Tipe Cb 061 Di PT. Amp Demak, Seminar Nasional IENACO - 2016, ISSN: 2337 4349, Semarang.

Soesilo, Rahman, 2017, Implementasi Kaizen dan 5S Pada Pengeringan Produk Di Proses Plating, Jurnal Teknik Industri, Vol. 18, No.02, Agustus 2017, PP. 121 126, ISSN: 1978-1431 print/ISSN 2527-4112 online, Jakarta.

Sudrajat, Fery Maulana, Faiza Renaldi, Fajri Rakhmat Umbara, 2018, Pembangunan Sistem Manajemen Rantai Pasok Dalam Proses Produksi Air Minum Dalam Kemasan Di PT. Multi Sinimar 
Jaya, Cimahi, Seminar Nasional Teknologi Informasi dan Multimedia 2018, 10 Februari 2018, ISSN: 2302-3805, Universitas AMIKOM Yogyakarta..

Sugiyono. 2015. Metode Penelitian (Kualitatif, Kuantitatif, dan $R \& D$ ), Cetakan ke-22. Penerbit: Alfabeta $\mathrm{CV}$, Bandung.

Suseno, Ari Zaqi Al Faritsy, 2015, Peningkatan Produktivitas Perusahaan Dengan Menggunakan Metode Six Sigma, Lean dan Kaizen, Jurnal Teknik Industri, Vol. X, No. 2, Mei 2015. Yogyakarta.

Tampubolon, Manahan P, 2014, Manajemen Operasi dan Pemasok (Operation and Supply Chain Management). Edisi Pertama, Jakarta. Penerbit. Mitra Wacana Media.
Westin, Maria, Diana Chronéer, Anders Segerstedt, 2013, Lean assembleto-order Manufacturing at Ericsson, Int. J. Logistics Systems and Management, Vol. 15, No. 1, 2013, Sweden.

Yamit, Zulian, 2005, Manajemen Produksi dan Operasi, Penerbit: Ekonisia, Yogyakarta.

Yohendry, Osrita Hapsara, Yunan Surono, 2017, Implementasi Kaizen Terhadap Efisiensi Biaya Produksi PT. Dasa Anugerah Sejati Asian Agri, J-MAS Vol.2 No.2, Oktober 2017, Jambi.

Zulfahmi, Rizqi Fauzi, Tacbir Hendro Pudjiantoro, Dian Nursantika, 2018, Pembangunan Sistem Manajemen Rantai Pasok dalam Proses Produksi Minuman Tradisional Di CV. Cihanjuang Inti Teknik, Seminar Nasional Teknologi Informasi dan Multimedia, 10 Februari 2018, ISSN: 2302-3805, Yogyakarta. 
